\title{
Recent advances in non-invasive diagnosis and medical management of non-alcoholic fatty liver disease in adult
}

\author{
Jayanta Paul(1)
}

\begin{abstract}
Background: Number of non-alcoholic fatty liver disease (NAFLD) cases is increasing over time due to alteration of food habit, increase incidence of metabolic syndrome, and lack of exercise. Liver biopsy is the test for diagnosis and staging of NAFLD, but nowadays several biochemical markers, scoring systems, and imaging studies are available to diagnose and stage NAFLD which is linked to end-stage liver disease, hepatocellular cancer, and elevated cardiovascular- and cancer-related morbidity and mortality. Therefore urgent diagnosis and management are required to avoid complications related to NAFLD. This review summarizes recent advances in diagnosis and medical management of non-alcoholic fatty liver disease.
\end{abstract}

Main text: Recently published studies from PubMed, Red Cross, Copernicus, and also various previous studies were reviewed. We have discussed various non-invasive methods for detection of non-alcoholic fatty liver disease, non-alcoholic steatohepatitis (NASH), and hepatic fibrosis. Non pharmacological therapies for NAFLD, indications, and approved medications for NAFLD and other commonly used non-approved medications have been discussed in this review article.

Conclusions: Multiple non-invasive tests are available for diagnosis of NAFLD, and its different stages however gold standard test is liver biopsy. NALFD without NASH and significant fibrosis is treated by lifestyle modifications which include moderate to vigorous exercise and diet modification. To improve hepatic steatosis, minimum of $3-5 \%$ of body weight loss is necessary, but $>7-10 \%$ weight reductions is required for histological improvement in NASH and fibrosis. Pharmacotherapy is indicated when patient is having NASH with significant fibrosis.

Keywords: NAFLD, NASH, Hepatic fibrosis, Recent advances in NAFLD, Non-invasive diagnosis of NAFLD, Medical management of NAFLD

\section{Background}

Incidence and prevalence of "Non-alcoholic fatty liver disease" (NAFLD) is increasing over time mainly due to bad food habit, weight gain, and sedentary lifestyle. NAFLD is the most common cause of abnormal liver function tests (LFTs) in the UK [1]. In the USA, prevalence of NAFLD is in between 10 and 30\%, which is similar to Asia and Europe [2, 3]. Singh et al. in 2004 [4]

Correspondence: dr.jayantapaul@gmail.com

Consultant Gastroenterologist and Liver Specialist, Department of Gastroenterology, Desun Hospital and Heart Institute, Kolkata 700124, India showed that $24.5 \%$ of healthy attendants had evidence of fatty liver on abdominal ultrasound. NAFLD is commonly associated with one or more component of metabolic syndrome such as obesity, diabetes mellitus, and dyslipidemia and is defined as the presence of $\geq 5 \%$ hepatic steatosis in histological examination without evidence of hepatocellular injury such as hepatocyte ballooning [5]. Around 20\% of patients with NAFLD develop non-alcoholic steatohepatitis (NASH) which may progress to cirrhosis [6], however most common cause of death in NAFLD patients is cardiovascular disease,

\section{Springer Open}

( ) The Author(s). 2020 Open Access This article is licensed under a Creative Commons Attribution 4.0 International License, which permits use, sharing, adaptation, distribution and reproduction in any medium or format, as long as you give appropriate credit to the original author(s) and the source, provide a link to the Creative Commons licence, and indicate if changes were made. The images or other third party material in this article are included in the article's Creative Commons licence, unless indicated otherwise in a credit line to the material. If material is not included in the article's Creative Commons licence and your intended use is not permitted by statutory regulation or exceeds the permitted use, you will need to obtain permission directly from the copyright holder. To view a copy of this licence, visit http://creativecommons.org/licenses/by/4.0/. 
and NAFLD is the third most common cause of hepatocellular carcinoma [5]. "Burned out" NAFLD can be a hidden cause of cryptogenic cirrhosis. So, early diagnosis, and treatment of NAFLD and underlying predisposing factors are important to avoid liver damage which may progress to liver failure.

\section{Diagnosis}

Liver biopsy is the gold standard test for diagnosis, grading, and histological assessment of NAFLD, and a fourpoint histopathologic grading system is used to assess severity of steatosis that ranges from 0 to 3 , depending on presence of the percentage of fat-containing hepatocytes (Table 1) [7]. But the value of a liver biopsy for the diagnosis of NAFLD in routine clinical practice is controversial, especially in the presence of a generally good prognosis for most patients with NAFLD, the lack of an established form of effective therapy, and the risks and costs associated with the liver biopsy.

Before considering the diagnosis of NAFLD, alcoholic fatty liver has to be excluded. Significant alcohol intake is considered when alcohol consumption $>7$ standard drinks/week (70 g ethanol) in women and > 14 (140 g ethanol) in men (according to Asia-Pacific Guidelines) or $>21$ standard drink on average per week in men and $>14$ standard drink per week in women (according to AASLD guidelines) or $>30 \mathrm{~g} /$ day in men and $>20 \mathrm{~g} /$ day in women (according to EASL guideline). One standard drink in Asia specific area and Europe is roughly $10 \mathrm{gms}$ of pure alcohol, however in USA it is 14 gms of pure alcohol. Therefore, patient should not take significant alcohol before diagnosis of NAFLD.

\section{Non-invasive tests for diagnosis of hepatic steatosis} Imagings for diagnosis of hepatic steatosis

Table 1 Histological and ultrasonographic grading of hepatic steatosis

\begin{tabular}{lll}
\hline $\begin{array}{l}\text { Grading of } \\
\text { hepatic } \\
\text { steatosis }\end{array}$ & $\begin{array}{l}\text { Histological } \\
\text { findings }\end{array}$ & Ultrasonographic findings \\
\hline $\begin{array}{l}\text { Grade 0 } \\
\text { steatosis }\end{array}$ & $\begin{array}{l}\text { Less than 5\% of } \\
\text { hepatocytes } \\
\text { contain fat }\end{array}$ & \\
Grade 1 & $\begin{array}{l}\text { 6-33\% of } \\
\text { hepatocytes } \\
\text { steatosis }\end{array}$ & $\begin{array}{l}\text { Hepatic echogenicity is more } \\
\text { than the renal cortex. }\end{array}$ \\
Grade 2 & $\begin{array}{l}34-66 \% \text { of } \\
\text { hepatocytes } \\
\text { contain fat }\end{array}$ & $\begin{array}{l}\text { Liver echogenicity obscures } \\
\text { echogenic wall of portal venous } \\
\text { branches. }\end{array}$ \\
Grade 3 & $\begin{array}{l}>66 \% \text { of } \\
\text { hepatocytes } \\
\text { steatosis }\end{array}$ & $\begin{array}{l}\text { Diaphragmatic wall and portal } \\
\text { venous walls are not visible due to } \\
\text { increased hepatic echogenicity. }\end{array}$ \\
\hline
\end{tabular}

A. Abdominal ultrasonography: Usually, "Hepatic steatosis" is diagnosed incidentally by abdominal ultrasonography (USG) which detect the increased echogenicity of the liver and divides fatty liver into three grades (Table 1) [8]. To identify hepatic steatosis, USG has sensitivity from 60 to $94 \%$ and specificity from 84 to $95 \%$ [9], and sensitivity is more than $90 \%$ when liver biopsy shows $>20 \%$ steatosis [10] (Fig. 1). Hepatorenal index of 1.34 or higher has sensitivity of $92 \%$ and specificity of $85 \%$ for identifying steatosis $>5 \%$ [11]. Another semiquantitative score (ultrasonographic fatty liver indicator) which requires the presence of liver/kidney contrast (brighter liver than kidney) among other parameters can detect NAFLD when score $\geq 2$ [12]. USG has several advantages (non-invasive test, widely available, low cost, quick diagnosis) and disadvantages (degree of fibrosis cannot be detected, low sensitivity when steatosis is less than $20 \%$, and limited use in obese individuals) for detection of fatty liver.

B. Controlled attenuation parameter: Transient elastography is an ultrasound-based study and also known as vibration-controlled transient elastography or Fibroscan which can measure controlled attenuation parameter (CAP). CAP which ranges from 100 to 400 decibels per meter $(\mathrm{dB} / \mathrm{m})$ can detect significant hepatic steatosis, but it is less accurate to distinguish between the different grades of hepatic steatosis [13]. However other studies indicate that CAP score is well correlated with steatosis grades in real-world clinical practice [14-16]. The optimal cut-off values of CAP for estimation of hepatic steatosis grades such as $\mathrm{S} 1, \mathrm{~S} 2$, and $\mathrm{S} 3$ are $\geq$ $263 \mathrm{~dB} / \mathrm{m}, \geq 281 \mathrm{~dB} / \mathrm{m}$ and $\geq 283 \mathrm{~dB} / \mathrm{m}$ respectively [13]. Another study also graded hepatic steatosis depending on CAP value into $\mathrm{S} 1 \geq 238 \mathrm{~dB} / \mathrm{m}, \mathrm{S} 2 \geq$ $260 \mathrm{~dB} / \mathrm{m}$, and $\mathrm{S} 3 \geq 293 \mathrm{~dB} / \mathrm{m}$ [17]. It does not predict liver-related events, non-hepatocellular carcinoma cancers, and cardiovascular events [18]. CAP showed excellent diagnostic performance for differentiating presence and absence of hepatic steatosis by using a cutoff value of $241 \mathrm{~dB} / \mathrm{m}$ in children with NAFLD but has limited value in evaluating grades of steatosis, especially in children with high BMI (> $30 \mathrm{~kg} / \mathrm{m}^{2}$ ) [19]. Before recommendation for hepatic steatosis measurement, CAP needs further validation.

C. Computed tomography (CT scan): Decreased attenuation of hepatic parenchyma compared to intrahepatic vessels, spleen, and kidney is detected in NAFLD by both contrast-enhanced and noncontrast CT scan. When hepatic density is higher than spleen, hepatic steatosis can be excluded. 


\begin{tabular}{|c|c|}
\hline \multicolumn{2}{|c|}{ Non Invasive tests for diagnosis of Hepatic steatosis } \\
\hline Imagings & Scoring Systems \\
\hline Abdominal ultrasonography & NAFLD liver fat score (NLFS) \\
\hline $\begin{array}{l}\text { 1. USG has sensitivity from } 60 \text { to } 94 \% \text { and specificity from } \\
84 \text { to } 95 \% \text {. } \\
\text { 2. } \\
\text { Sensitivity is }>90 \% \text { when liver biopsy shows }>20 \% \\
\text { steatosis. }\end{array}$ & $\begin{array}{l}\text { 1. NLFS value }>-0.640 \text { has a sensitivity of } 86 \% \text { and } \\
\text { specificity of } 71 \% \text { to identify hepatic steatosis }> \\
5.56 \% \text {. }\end{array}$ \\
\hline $\begin{array}{l}\text { Hepatorenal index of } 1.34 \text { or higher has sensitivity of } 92 \% \\
\text { and specificity of } 85 \% \text { for identifying steatosis } \geq 5 \% \text {. }\end{array}$ & 2. Different stages of NAFLD cannot be distinguished. \\
\hline $\begin{array}{l}\text { 4. Ultrasonographic Fatty Liver Indicator score } \geq 2 \text { indicates } \\
\text { NAFLD. }\end{array}$ & $\begin{array}{l}\text { 3. Higher NLFS is associated with increased liver } \\
\text { disease mortality. }\end{array}$ \\
\hline Controlled Attenuation Parameter & Fatty liver index (FLI) \\
\hline $\begin{array}{l}\text { The optimal cut-off value of CAP to estimate hepatic } \\
\text { steatosis grades: } \\
\text { 1. } \text { CAP value } \geq 238 \mathrm{~dB} / \mathrm{m}: \text { S1 (Grade } 1) \\
\text { 2. } \\
\text { 3. }\end{array}$ & $\begin{array}{l}\text { 1. Fatty liver index: }<30 \text { rules out fatty liver and value } \\
\geq 60 \text { rules in fatty liver (sensitivity: } 86 \% \text { and } \\
\text { specificity } 87 \% \text { ) }\end{array}$ \\
\hline Computed tomography scan (CT Scan) & Hepatic steatosis Index (HSI) \\
\hline $\begin{array}{l}\text { Moderate-to-severe hepatic steatosis can be identified } \\
\text { when-- } \\
\text { 1. liver attenuation value }<40-42 \mathrm{HU} \text { or } \\
\text { 2. Hepatic-spleenic attenuation ratio is }<0.8 \text {. }\end{array}$ & $\begin{array}{l}\text { 1. HSI (value }<30 \text { ) excludes hepatic steatosis with } \\
93.1 \% \text { sensitivity or } \\
\text { 3. HSI (value }>36 \text { ) detects hepatic steatosis with a } \\
\text { specificity of } 92.4 \% \text {. }\end{array}$ \\
\hline Magnetic resonance imaging (MRI) & Lipid accumulation product (LPA) \\
\hline $\begin{array}{l}\text { 1. MRI to detect histologically confirmed hepatic steatosis: } \\
\text { 2ensitivity ( } 76.7 \text { to } 90.0 \% \text { ) and Specificity ( } 87.1 \text { to } 91 \% \text { ) } \\
\text { 2. Can detect liver fat as low as } 5 \%-10 \% \text {. } \\
\text { 3. Hydrogen-1 MR spectroscopy (H-MHS) is a non-invasive } \\
\text { technique which can diagnose and quantify hepatic } \\
\text { steatosis into three grades. } \\
\text { 4. Proton density fat fraction (PDFF) with MRI: It is an } \\
\text { accurate biomarker of hepatic steatosis and can } \\
\text { discriminate different grades of hepatic steatosis with a } \\
\text { good diagnostic accuracy. } \\
\text { 5. Hepatic phosphorus-31 MRS ( } 31 \text { P MRS) shows promise } \\
\text { in the differentiation of NAFLD stages. }\end{array}$ & $\begin{array}{l}\text { 1. Cut-off value of LAP for detection of hepatic steatosis } \\
\text { in men is } 30.5 \text { (sensitivity: } 77 \% \text {, specificity: } 75 \% \text { ). } \\
\text { 2. Cut-off value of LAP for detection of hepatic steatosis } \\
\text { in women is } 23.0 \text { (sensitivity: } 82 \% \text {, specificity: } 79 \% \text { ). }\end{array}$ \\
\hline Xenon-133 liver scan & SteatoTest \\
\hline \multirow[t]{3}{*}{$\begin{array}{l}\text { 1. It is superior to ultrasound with a sensitivity of } 94.3 \% \text { and } \\
\text { specificity of } 87.5 \% \text {. } \\
\text { 2. More accurate to detect mild grade of steatosis. } \\
\text { 3. It is not expected to distinguish between different } \\
\text { subtypes of NAFLD. } \\
\text { 4. It does not provide information of liver morphology. }\end{array}$} & $\begin{array}{l}\text { 1. A cut-off value of } 0.30 \text { has } 90 \% \text { sensitivity to detect } \\
\text { hepatic steatosis. } \\
\text { 2. A cut-off of } 0.72 \text { has } 90 \% \text { specificity to diagnose } \\
\text { hepatic steatosis }\end{array}$ \\
\hline & NAFL screening score \\
\hline & $\begin{array}{l}\text { 1. The lower cut-off value with a sensitivity of } 92 \% \text { and } \\
\text { negative predictive value of } 95 \% \text { is } 0.24 \\
\text { 2. The high cut-off value with } 90 \% \text { specificity and } \\
\text { positive predictive value of } 84 \% \text { is } 0.44\end{array}$ \\
\hline
\end{tabular}

Fig. 1 Non invasive tests for diagnosis of hepatic steatosis 
Hepatic steatosis can be detected in CT scan of the abdomen when spleen attenuation $>$ liver attenuation or when liver attenuation value $<48$ Hounsfield units (HU) [20]. Moderate-to-severe hepatic steatosis can be identified with a specificity of 100\% when liver attenuation value is $<40-42 \mathrm{HU}$ and hepatic-spleenic attenuation ratio is $<0.8$ [21]. Qualitative evaluation of the liver on a portal venous phase contrast-enhanced CT is highly specific to detect hepatic steatosis, but sensitivity (around $60 \%$ ) is low. CT scan has several limitations such as limited accuracy to detect mild degree hepatic steatosis, risk of radiation exposure, high cost, and availability. CT scan is commonly used to detect hepatic steatosis for living liver donor candidate [22]. Dual energy CT (DECT) findings are strongly correlated with histopathologic findings in cases of steatosis and can allow rapid, accurate evaluations of hepatic steatosis.

D. Magnetic resonance imaging (MRI): MRI is considered as the most definitive imaging study for qualitative and quantitative assessment of hepatic steatosis. The sensitivity and specificity of MRI to detect histologically confirmed hepatic steatosis are 76.7 to $90.0 \%$ and 87.1 to $91 \%$, respectively [7, 23]. Frequency-selective MRI, chemical-shift-encoded MRI, MR spectroscopy, and magnetic resonance elastography techniques are usually used to assess hepatic fat content [24]. In MRI, both in-phase (IP) and out-of-phase (OOP) imaging to be adequately assessed to detect fatty liver (FL), and in out-ofphase image FL appears as hyper intense (in T1 image), mildly hyper intense (in T2 image), and signal droop out (signal loss is demonstrated when there is $10-15 \%$ fat fraction with maximum signal loss occurring when there is $50 \%$ fatty infiltration of the liver). Advantages of MRI-based detection of fatty liver are no radiation exposure; high diagnostic accuracy; can detect fat as low as 5-10\%; operator independent; highly responsive to changes in steatosis throughout parenchyma; and not significantly impacted by demographics, histologic activity, or co-existing hepatic conditions. It has the following disadvantages: high cost and taking long time. Hydrogen-1 MR spectroscopy (1H-MRS) is a noninvasive technique which can diagnose and quantify hepatic steatosis into three grades, and H-MHS thresholds correspond with histopathologic grading of steatosis and may obviate liver biopsy (Table 2) [25]. 1H-MRS allows the direct measurement of the area under the lipid resonance peak. This test result is not modified by the presence of confounding factors such as fibrosis, iron overload, and glycogen. Main drawbacks of H-MHS are high cost, less
Table 2 Hydrogen-1 MR spectroscopy grading of fatty liver

\begin{tabular}{ll}
\hline Grading of fatty liver & Hydrogen-1 MR spectroscopy findings \\
\hline Grade 0 steatosis & $\begin{array}{l}\text { Proton density fat fraction threshold of less } \\
\text { than 17.0\% }\end{array}$ \\
Grade 1 steatosis & $\begin{array}{l}\text { Proton density fat fraction threshold of 17.0- } \\
38.6 \%\end{array}$ \\
$\begin{array}{l}\text { Grade 2 or greater } \\
\text { steatosis }\end{array}$ & $\begin{array}{l}\text { Proton density fat fraction threshold greater } \\
\text { than 38.6\% }\end{array}$ \\
\hline
\end{tabular}

availability, complex technique requiring patient cooperation, samples only a small portion of the entire liver, and not well validated and still considered a research tool.

Proton density fat fraction (PDFF) in MRI is also used for quantifying hepatic steatosis. PDFF is an accurate marker of hepatic steatosis and allows discriminating with a good diagnostic accuracy between different grades of hepatic steatosis [26]. The accuracy of PDFF measurement using chemical shift-encoded methods is similar to that of MRS. Recently, hepatic phosphorus-31 MRS (31P-MRS) is proposed in different studies as a potential marker to detect distinct biochemical changes in different NAFLD states. It shows promise in the differentiation of NAFLD stages [27].

E. Xenon-133 liver scan: Xe-133 liver scan is a safe, reliable, non-invasive method with low radiation exposure to detect and quantify hepatic steatosis, and is superior to ultrasound with a sensitivity of $94.3 \%$ and specificity of $87.5 \%$ [28]. Compared with other imaging investigations, Xe-133 scan is more accurate to detect mild grade of steatosis [28]. One major limitation of Xe-133 scan is that it only detects fat; therefore, it is not expected to distinguish between different subtypes of NAFLD and does not provide information of liver morphology. The usefulness of Xe-133 scan in the diagnosis of NAFLD has not been well studied till now (Fig. 1).

\section{Non-invasive scoring systems for diagnosis of hepatic steatosis}

There is no single laboratory marker that can be used for the diagnosis of NAFLD. Gamma-glutamyltransferase (GGT) in the serum is frequently elevated in NAFLD patients and associated with increased mortality [29], however does not help in diagnosis of NAFLD. Alanine aminotransferase (ALT) and aspartate aminotransferase (AST) levels are not sensitive for diagnosis of NAFLD. Following scoring systems are available to identify NAFLD.

A. NAFLD liver fat score (NLFS): The NAFLD liver fat score is estimated by using the presence of the metabolic syndrome, type 2 diabetes, fasting serum insulin level, fasting serum AST, and the AST/ALT 
ratio [30]. NLFS value $>-0.640$ has a sensitivity of $86 \%$ and specificity of $71 \%$ to identify hepatic steatosis $>5.56 \%$ [30]. However, by this scoring system, different stages of NAFLD cannot be distinguished. This score provide simple and noninvasive tool to predict NAFLD and liver fat content. Higher NLFS is associated with increased liver disease mortality but not with other mortality outcomes [31].

B. Fatty liver index (FLI): Fatty liver index is a suitable and simple predictor for hepatic steatosis. FLI is calculated by measuring waist circumference, body mass index, serum triglyceride, and gammaglutamyltransferase [32]. Score varies from zero to 100. Fatty liver index $<30$ rules out fatty liver, but value $\geq 60$ rules in fatty liver with a sensitivity and specificity of $86 \%$ and $87 \%$, respectively [32]. FLI independently associates with overall, cardiovascular and cancer-related mortality. FLI can serve as a surrogate marker for hepatic steatosis and metabolic syndrome in type 1 diabetes [33].

C. Hepatic steatosis index (HSI): It is a simple, effective NAFLD screening tool derived by a logistic regression model. It includes gender, history of T2DM, body mass index (BMI), alanine transaminase (ALT), and aspartate transaminase (AST). HSI is calculated by the following formula: 8 $\times$ (ALT/AST ratio) + BMI (addition of +2 if female; +2 if diabetes mellitus) [33]. HSI value $<30$ excludes NAFLD with $93.1 \%$ sensitivity and value > 36 detects NAFLD with a specificity of $92.4 \%$ [23]. It may be utilized for selecting individuals for hepatic USG and for determining the need of lifestyle modifications.

D. Lipid accumulation product (LAP): It is significantly associated with the presence of liver steatosis and has a high diagnostic accuracy to identify NAFLD in the general population, and diagnostic accuracy is higher in young age group individuals [34, 35]. Following calculation is used to measure LAP: [waist circumference $(\mathrm{cm})-65$ ] $\times$ triglyceride concentration $(\mathrm{mmol} / / \mathrm{L})$ in men and [waist circumference $(\mathrm{cm})-58] \times$ triglyceride concentration $(\mathrm{mmol} / \mathrm{L})$ in women [35]. Cutoff values of LAP in men and women are 30.5 (sensitivity $77 \%$, specificity $75 \%$ ) and 23.0 (sensitivity $82 \%$, specificity $79 \%$ ), respectively [35]. Although this is a very simple and low cost test, it needs further validation before recommendation. Lipid accumulation product can also predict metabolic syndrome in individuals without fatty liver disease [36].

E. SteatoTest: SteatoTest includes ten components such as serum $\alpha 2$-macroglobulin, apo A1, haptoglobin, total bilirubin, GGT, ALT, body mass index, serum cholesterol, triglycerides, and glucose adjusted for age and gender. It is a simple and noninvasive method to identify liver steatosis and may reduce the need for liver biopsy, particularly in patients with component of metabolic syndrome [37]. A cutoff of 0.30 has $90 \%$ sensitivity, and a cutoff of 0.72 has $90 \%$ specificity to diagnose hepatic steatosis [37]. It needs further validation before recommendation.

F. NAFL screening score: It is a model to detect NAFLD with the following six components: age, fasting blood glucose, BMI, triglyceride, ALT/AST, and uric acid. The lower cutoff value with a sensitivity of $92 \%$ and negative predictive value of $95 \%$ is 0.24 , and the high cutoff value with $90 \%$ specificity and $84 \%$ positive predictive value is 0.44 [38].

\section{Non-invasive tests for diagnosis of non-alcoholic steatohepatitis (NASH)}

NASH can progress to cirrhosis and its complications such as portal hypertension, liver failure, and hepatocellular carcinoma. Cirrhosis develops in 21 to $28 \%$ of NASH patients compared to only $3 \%$ of patients with nonalcoholic fatty liver. The gold standard for diagnosis of NASH is liver biopsy. But liver biopsy is an invasive procedure and has several complications, non-invasive tests has been developed for diagnosis of NASH (Fig. 2).

\section{Serum biomarkers}

A. Serum cytokeratin (CK)-18: It is a marker of hepatocyte apoptosis, most widely investigated for diagnosis of NASH and is the most consistent single parameter for differentiating steatosis from NASH [39]. Cutoff value of CK-18 > 240 U/L has a sensitivity of $76.7 \%$ and specificity of $95.0 \%$ for diagnosis of NASH [40]. Another study showed that optimal cutoff point of serum CK-18-fragments for definite NASH was $270 \mathrm{U} / \mathrm{L}$ with sensitivity and specificity of $64 \%$ and $76 \%$, respectively [41].

B. Serum aminotransferases: It is commonly used in clinical practice as a surrogate marker for liver inflammation but has poor predictive value for diagnosis of NASH [5]. Serum alanine aminotransferase (ALT) value $>2$ times the upper limit of normal (> $70 \mathrm{U} / \mathrm{L})$ has a sensitivity of $50 \%$ and specificity of $61 \%$ for NASH detection [42], but $\sim 80 \%$ of patients with fatty liver have shown ALT levels within normal limits [43]. Aminotransferase levels do not correlate with the degree of hepatic fibrosis. Liver enzymes should not be used for detection of NASH. Further studies are required to 


\begin{tabular}{|c|c|c|}
\hline \multicolumn{3}{|c|}{ Non invasive tests for diagnosis of steatohepatitis (NASH) } \\
\hline Serum Biomarkers & Non-invasive scoring systems & Imagings \\
\hline Serum cytokeratin (CK)-18 & NASH test & $\begin{array}{l}\text { Proton magnetic resonance } \\
\text { (1H-MRS) }\end{array}$ \\
\hline $\begin{array}{l}\text { 1. Cut-off value of CK-18 is }>240 \mathrm{U} / \mathrm{L} \text { for } \\
\text { diagnosis of NASH (sensitivity: } 76.7 \% \\
\text { and specificity: } 95.0 \% \text { ). } \\
\text { 2. Most consistent single parameter for } \\
\text { differentiating steatosis from NASH. }\end{array}$ & $\begin{array}{ll} & \text { It divides NASH into three } \\
\text { categories: } \\
\text { 1. } \\
\text { 2. }\end{array}$ & $\begin{array}{l}\text { This method is studied in } \\
\text { detecting NASH with a } \\
\text { sensitivity of } 87.4 \% \text { and } \\
\text { specificity of } 74.3 \%\end{array}$ \\
\hline Serum aminotransferases & NASH diagnostic index (NDI) & \multirow{2}{*}{$\begin{array}{l}\text { Magnetic resonance } \\
\text { elastography (MRE) }\end{array}$} \\
\hline \multirow{2}{*}{$\begin{array}{l}\text { Serum alanine aminotransferase (ALT) } \\
\text { value }>2 \text { times the upper limit of normal } \\
(>70 \mathrm{U} / \mathrm{L}) \text { has a sensitivity of } 50 \% \text { and } \\
\text { specificity of } 61 \% \text { for NASH detection. }\end{array}$} & \multirow{2}{*}{$\begin{array}{l}\text { NDI value } \geq 22 \text { has a specificity of } \\
82 \% \text { for identifying a diagnosis of } \\
\text { simple steatosis }\end{array}$} & \\
\hline & & \\
\hline \multirow{4}{*}{$\begin{array}{l}\text { 2. } \begin{array}{l}\text { so\% of patients with fatty liver have } \\
\text { shown ALT levels within normal limits. }\end{array} \\
\text { 3 Aminotransferase levels do not correlate } \\
\text { 4. with the degree of hepatic fibrosis. }\end{array}$} & $\begin{array}{l}\text { 2. NDI value } \geq 50 \text { has a specificity of } \\
86 \% \text { for diagnosing histologically } \\
\text { confirmed NASH }\end{array}$ & \multirow{4}{*}{$\begin{array}{l}2 \text { Differentiate NASH from } \\
\text { NAFL with a sensitivity of } \\
94 \% \text { and specificity } 73 \% \text { by } \\
\text { using a threshold of } 2.74 \\
\mathrm{kPa}\end{array}$} \\
\hline & HAIR score & \\
\hline & $\begin{array}{l}\text { 1. The presence of } \geq 2 \text { parameters } \\
\text { predict NASH (sensitivity of } 80 \% \\
\text { and specificity of } 89 \% \text { ) }\end{array}$ & \\
\hline & Nice model & \\
\hline Serum Adiponectin & Cut off value is 0.14 for diagnosis & \multirow[t]{3}{*}{ Breath test } \\
\hline $\begin{array}{l}\text { 1. Cut-off negative predictor for NASH is } \\
29.16 \mu \mathrm{g} / \mathrm{L} \text {. }\end{array}$ & $\begin{array}{l}\text { of NASH ( } 84 \% \text { sensitivity, } 86 \% \\
\text { specificity) }\end{array}$ & \\
\hline Fibroblast growth factor 21 (FGF21) & Palekar score & \\
\hline \multirow[t]{2}{*}{$\begin{array}{l}\text { 1. Its level correlates with severity of } \\
\text { steatohepatitis in patients with NASH. } \\
\text { 2. FGF21 level may help to identify patients } \\
\text { who is having highest risk of disease } \\
\text { progression. }\end{array}$} & $\begin{array}{l}\text { 1. } \geq 3 \text { risk factors distinguishes NASH } \\
\text { from steatosis ( } 73.7 \% \text { sensitivity, } \\
65.7 \% \text { specificity) }\end{array}$ & \multirow{16}{*}{$\begin{array}{ll}1 & \begin{array}{l}\text { Analyzing three volatile } \\
\text { organic compounds (n- } \\
\text { tridecane, 3-methyl- } \\
\text { butanonitrile, and 1- } \\
\text { propanol) in the exhaled } \\
\text { breath }\end{array} \\
2 & \begin{array}{l}\text { Distinguishes patients with } \\
.\end{array} \\
\text { NASH from without NASH } \\
3 & \begin{array}{l}\text { Negative predictive value of } \\
82 \% \text { and positive predictive } \\
\text { value } 81 \%\end{array}\end{array}$} \\
\hline & NASH ClinLipMet score & \\
\hline $\begin{array}{c}\text { Proprotein convertase subtilisin/kexin } \\
\text { type } 9 \text { (PCSK9) }\end{array}$ & $\begin{array}{l}\text { 1. The sensitivity of this scoring } \\
\text { system is } 75 \% \text {. }\end{array}$ & \\
\hline $\begin{array}{l}\text { 1. Circulating PCSK9 increases with hepatic } \\
\text { fat accumulation. }\end{array}$ & $\begin{array}{l}\text { This test is usually is used in } \\
\text { research because of high cost. }\end{array}$ & \\
\hline 2. Correlates with the severity of steatosis. & NASH predictive index (NPI) & \\
\hline Plasma pentraxin 3(PTX3) & $\begin{array}{l}\text { Predicting the presence of NASH, } \\
\text { this index is promising (AUROC of }\end{array}$ & \\
\hline 1. Higher serum concentration is seen in & 0.87 to 0.90$)$ & \\
\hline NAFLD. & NAFIC score & \\
\hline Malondialdehyde (MDA) & This score includes ferritin, fasting & \\
\hline $\begin{array}{l}\text { 1. High serum level is seen in patients with } \\
\text { NASH than without NASH }\end{array}$ & insulin, and type IV collagen 7S. & \\
\hline Tumor Necrosis Factor Alpha (TNF- $\alpha)$ & Gholam score & \\
\hline \multirow{3}{*}{$\begin{array}{l}\text { It is elevated in patients with NASH. } \\
\text { 2. High level of TNF- } \alpha \text { has increased higher } \\
\text { adverse hepatic events risk compared to } \\
\text { patients with low level of TNF- } \alpha\end{array}$} & NASH Score & \\
\hline & oxNASH score & \\
\hline & $\begin{array}{l}\text { 1. Score }>72 \text { were } 10 \text { times more } \\
\text { likely to have NASH }\end{array}$ & \\
\hline Interleukin-6 (IL-6) & & \\
\hline $\begin{array}{l}\text { 1. IL-6 is positively correlated with severity } \\
\text { of hepatocyte inflammation, stage of } \\
\text { fibrosis in patients with NASH. }\end{array}$ & & \\
\hline
\end{tabular}

Fig. 2 Non invasive tests for diagnosis of non alcoholic steatohepatitis 
find out cutoff value of liver enzymes to prevent unnecessary diagnostic work-ups and early detection of NASH.

C. Serum adiponectin: Adiponectin is exclusively synthesized by adipose tissue and involves in glucose and lipid metabolism. It is a negative predictor of NASH in fatty liver patients with a cutoff value $29.16 \mu \mathrm{g} / \mathrm{L}$ [44].

D. Fibroblast growth factor 21 (FGF21): Serum FGF21 level correlates with severity of steatohepatitis in patients with NASH, and its level may help to identify patients who are having highest risk of disease progression. Plasma FGF21 was higher in patients with NASH with mean value of $453 \pm 262$ $\mathrm{pg} / \mathrm{mL}$ when compared to patients without NASH [45]. To improve the positive predictive value (PPV) and negative predictive value (NPV) of FGF21, CK18 is combined with FGF21, which improves the PPV to $82 \%$ and NPV to $74 \%$ [46].

E. Proprotein convertase subtilisin/kexin type 9 (PCSK9): Hepatocytes secrete PCSK9 which inhibits the uptake of low-density lipoproteins by targeting the receptor for degradation and possibly lipogenesis. In a recent study, Paquette et al. described strong association between PCSK9 and liver biomarkers as well as hepatic steatosis [47]. Circulating PCSK9 increases with hepatic fat accumulation and also correlates with the severity of steatosis [48].

F. Plasma pentraxin 3(PTX3): Higher serum concentration of pentraxin 3 protein is seen in patients with more advanced stages of NAFLD, and higher values are correlated with advanced stages of the hepatic fibrosis. Therefore, serum PTX3 level could be used as a marker to assess severity of hepatic fibrosis [49].

G. Malondialdehyde (MDA): High serum level of malondialdehyde is seen in type 2 diabetes patients with NASH than without NASH [50]. MDA can stimulate hepatic stellate cells and result in fibrosis.

H. Tumor necrosis factor alpha (TNF- $\alpha$ ): Tilg et al. described that TNF- $\alpha$ is elevated in serum of those with NASH [51]. Patients with high level of TNF- $\alpha$ have increased burden of NAFLD and higher adverse hepatic event risk compared to patients with low level of TNF- $\alpha$ [51].

I. Interleukin-6 (IL-6): Elevated serum IL-6 is associated with an increased likelihood of exhibiting NAFLD. IL-6 is positively correlated with severity of hepatocyte inflammation, stage of fibrosis in patients with NASH [52]. However, Yoneda et al. in their study did not find any increase in expression of IL-6 in patients with steatohepatitis as compared to patients with simple hepatic steatosis [53].

\section{Non-invasive scoring systems for diagnosis of steatohepatitis (NASH)}

A. NASH test: NASH test is a simple and non-invasive scoring system to predict the presence or absence of NASH in patients with non-alcoholic fatty liver disease [54]. It includes 13 components (age, sex, height, weight, serum levels of triglycerides, cholesterol, a2-macroglobulin, apolipoprotein A1, haptoglobin, g-glutamyltransferase, aminotransferases ALT, AST, and total bilirubin) to identify NASH and divide $\mathrm{NASH}$ into three categories: NASH (AUROC of 0.79), Borderline NASH (AUROC of 0.69), and No-NASH (AUROC of 0.77-0.83) [55].

B. HAIR score: This score depends on the following parameters: hypertension, alanine aminotransferase [ALT] level, and insulin resistance. The presence of at least two of the three parameters provides the best combination of sensitivity of $80 \%$ and specificity of $89 \%$ for predicting NASH especially in severely obese individuals [56].

C. NASH diagnostic index (NDI): This index is calculated by serum insulin, glucose, triglycerides, ALT, and waist-to-hip ratio. By using a value $\geq 22$, NDI has a specificity of $82 \%$ for establishing a diagnosis of simple steatosis, and NDI has a specificity of $86 \%$ for diagnosing NASH when value is $\geq 50$ [57].

D. NICE model: A simple and non-invasive composite model includes metabolic syndrome (MS), CK-18, and serum ALT level. This model is designed to diagnose NASH in morbidly obese patients. The equation of "Nice model" is: $-5.654+3.780 \mathrm{E}-02 \times$ ALT $(\mathrm{IU} / \mathrm{L})+2.215 \mathrm{E}-03 \times$ CK18 fragment levels $(\mathrm{IU} / \mathrm{L})+1.825 \times($ presence of MS $=1)$ [58]. The best cutoff value is 0.14 for diagnosis of NASH and this value is associated with $84 \%$ sensitivity, $86 \%$ specificity, $44 \%$ positive predictive value, and $98 \%$ negative predictive value.

E. Palekar score: It was proposed to distinguish NASH from steatosis. This scoring system includes the following risk factors: age $\geq 50$ years, female gender, AST $\geq 45 \mathrm{IU} / \mathrm{L}$, body mass index (BMI) $\geq 30 \mathrm{mg} /$ $\mathrm{kg} 2$, AST/ALT ratio $\geq 0.80$, and hyaluronic acid $\geq$ $55 \mu \mathrm{g} / \mathrm{L}$. The presence of three or more risk factors has $73.7 \%$ sensitivity and $65.7 \%$ specificity to distinguish NASH from steatosis [59].

F. NAFIC score: This score is used by using ferritin, fasting insulin, and type IV collagen $7 \mathrm{~S}$ for predicting non-alcoholic steatohepatitis in NAFLD patients [60].

G. NASH ClinLipMet score: This test is used by utilizing serum AST value, fasting insulin value, PNPLA3 genotype, glutamate, isoleucine, glycine, 
lysophosphatidylcholine 16:0, and

phosphoethanolamine 40:6. The sensitivity of this scoring system is 75\% [55]. This test is usually used in research because of high cost.

H. NASH predictive index (NPI): This index is used by using age, female gender, body mass index (BMI), homeostatic model assessment (HOMA) of insulin resistance, and log [aspartate aminotransferase $(\mathrm{AST}) \times \mathrm{ALT}]$. For predicting the presence of $\mathrm{NASH}$, this index is promising (AUROC of 0.87 to 0.90) but lacks external validation [61].

I. Other scoring systems: Gholam score (AST and diabetes mellitus) [62] and oxNASH (13-hydroxyloctadecadienoic acid/linoleic acid ratio, age, BMI, and AST) score $>72$ were 10 times more likely to have NASH compared to those with oxNASH score $<47$ [63], and a clinical score by Chunming et al. [64] including ALT, gamma-glutamyl transpeptidase, $\mathrm{C}$-reactive protein, and $\mathrm{ApoB} / \mathrm{ApoA} 1$ ratio, NASH Score [65] (AST, PNPLA3 genotype and fasting insulin) were studied for identification of NASH.

\section{Breath test for diagnosis of non-alcoholic steatohepatitis} A study showed that analyzing three volatile organic compounds (n-tridecane, 3-methyl-butanonitrile, and 1propanol) in the exhaled breath were sufficient to distinguish patients with NASH from without NASH with negative and positive predictive values of $82 \%$ and $81 \%$, respectively [66].

\section{Imagings for diagnosis of non-alcoholic steatohepatitis} Routine imaging techniques (Ultrasonography, CT, or MRI) are unable to differentiate NASH from simple steatosis.

A. Proton magnetic resonance (1H-MRS): This method is studied in detecting NASH with a sensitivity of $87.4 \%$ and specificity of $74.3 \%$ [67].

B. Magnetic resonance elastography (MRE): MRE can accurately identify NASH prior to fibrosis and differentiate NASH from NAFL with a sensitivity of $94 \%$ and specificity $73 \%$ by using a threshold of $2.74 \mathrm{kPa}[68]$. But it needs further validation.

\section{Non-invasive tests for diagnosis of hepatic fibrosis:}

Stages of liver fibrosis are the most important factor for the prognosis of NAFLD and predicting the risk of progression to cirrhosis and its complications. There are several predictive models available to identify hepatic fibrosis (Fig. 3).

\section{Non-invasive scoring systems for diagnosis of hepatic fibrosis}

A. AST/platelet ratio index (APRI): This is measured by using the patient's AST level, upper limit of normal AST value, and platelet count. APRI cutoff of $\geq 0.7$ has a sensitivity of $77 \%$ and specificity of $72 \%$ to detect significant hepatic fibrosis ( $\geq$ F2 by Metavir) and a cutoff score of at least 1.0 has a sensitivity of 61 to $76 \%$ and specificity of 64 to $72 \%$ for detection of severe fibrosis/cirrhosis (F3 to F4 by Metavir) [69]. APRI has a good negative predictive value to exclude advanced fibrosis but does not accurately differentiate intermediate fibrosis from mild or severe fibrosis.

B. FIB-4: It is a simple, accurate, and inexpensive method for assessing liver fibrosis and includes the following components: age, platelet count, AST, and ALT. It is calculated by using [age (years) $\times$ AST $(\mathrm{U} / \mathrm{L})] /\left[\right.$ number of platelets $\left(10^{9} / \mathrm{L}\right) \times \operatorname{ALT}(\mathrm{U} / \mathrm{L})$ $(1 / 2)$ ] formula. An FIB-4 score $>3.25$ has a positive predictive value of $82.1 \%$ with a specificity of $98.2 \%$ to confirm the existence of a significant fibrosis (F3F4 by Metavir) [70]. FIB-4 has high negative predictive value (>90\%) for ruling out advanced fibrosis when score is $<1.45$.

C. BARD score: This is calculated by using the sum of 3 variables (BMI $\geq 28=1$ point, AST-to-ALT Ratio $\geq 0.8=2$ points, the presence of diabetes $=1$ point), and score $\geq 2$ is associated with advanced fibrosis [71]. Due to its simplicity, it is popular among general practitioners, However due to its low positive predictive value $(<42 \%)$ it includes many patients without NASH/ fibrosis into high risk group and limits its utility in clinical practice.

D. NAFLD fibrosis score (NFS): A simple scoring system accurately separates NAFLD with and without advanced fibrosis. It includes age, hyperglycemia, body mass index, platelet count, albumin, and AST/ALT ratio as variables. By using low cutoff score of -1.455 , advanced hepatic fibrosis could be excluded with high negative predictive value of $93 \%$, and by applying the high cutoff score of 0.676 , advanced hepatic fibrosis could be diagnosed with high positive predictive value of $90 \%$ [72]. Advantages of the NFS are as follows: (1) its ability to provide prognostic information and (2) identify NAFLD patients who are at increased risk for liver-related complications such as ascites and gastroesophageal varices or death.

E. King's score: The King's score is a simple index for predicting cirrhosis and calculated by the following formula: age $\times$ AST $(\mathrm{U} / \mathrm{L}) \times \mathrm{INR} /$ platelet count 


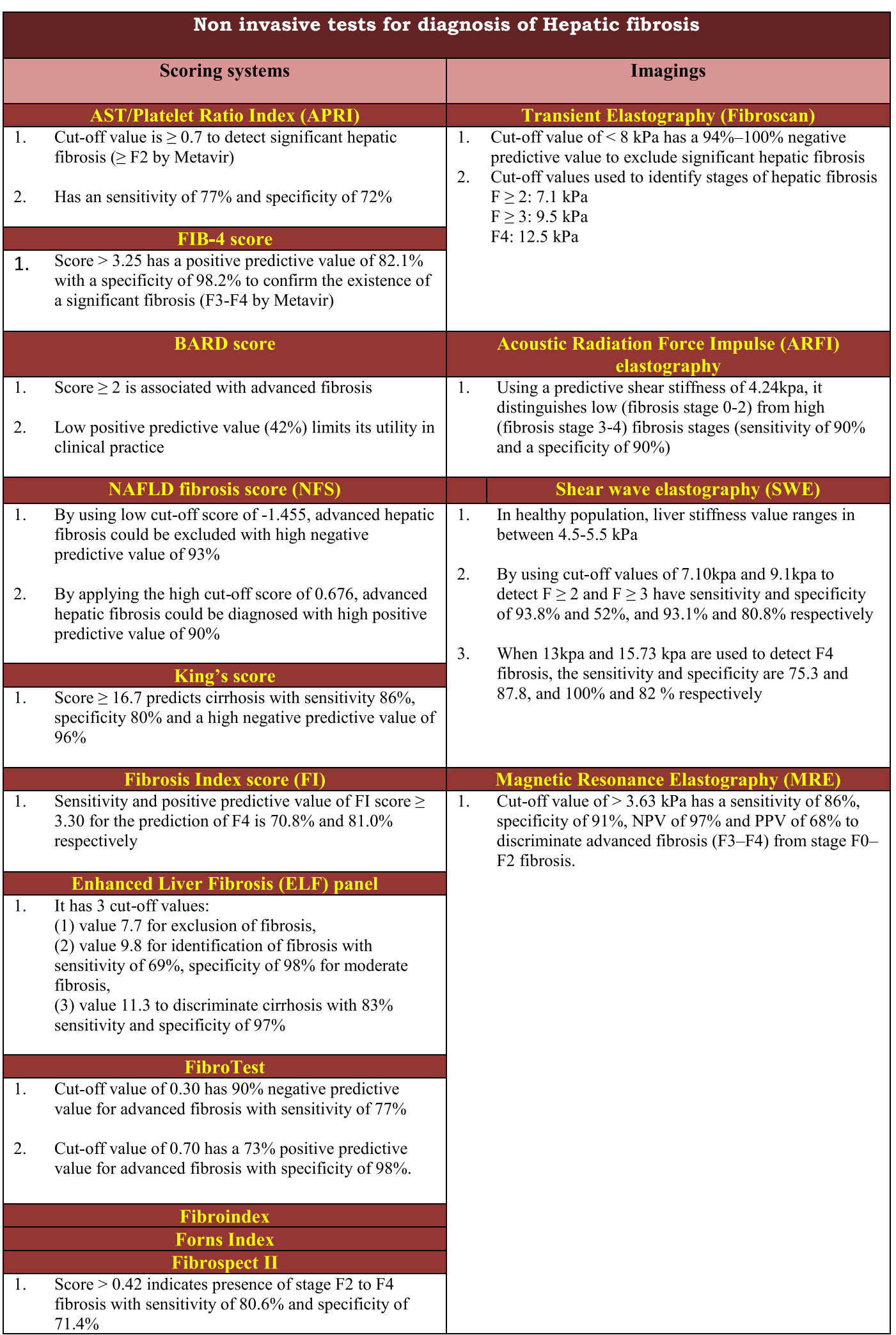

Fig. 3 Non invasive tests for diagnosis of hepatic fibrosis 
$\left(10^{9} / \mathrm{L}\right)$. Score of $\geq 16.7$ predicts cirrhosis with sensitivity $86 \%$, specificity $80 \%$, and a high negative predictive value of $96 \%$ [73]. This score was initially evaluated for diagnosis of cirrhosis in patients with hepatitis $\mathrm{C}$ infection.

F. Fibrosis index score (FI): This is a simple index to detect hepatic fibrosis noninvasively and measured by " $8-0.01 \times$ number of platelets $\left(10^{9} / \mathrm{L}\right)$ - albumin $(\mathrm{g} / \mathrm{dL})$ " formula. Sensitivity and positive predictive value of FI score $\geq 3.30$ for the prediction of $\mathrm{F} 4$ is $70.8 \%$ and $81.0 \%$, respectively [74].

G. Cao et al. published a score by measuring CK-18, ALT, platelets, and triglycerides that had significant positive correlation with staging hepatic fibrosis [75].

H. Egy-Score: This score is a useful non-invasive panel of surrogate biomarkers that can accurately predict stages of hepatic fibrosis. Egy-Score was calculated by the following formula: $3.52+0.0063 \times$ CA19-9 + $0.0203 \times$ age $+0.4485 \times$ alpha-2-macroglobulin + $0.0303 \times$ bilirubin $-0.0048 \times$ platelet $-0.0462 \times$ albumin [76].

I. Enhanced liver fibrosis (ELF) panel: It includes three variables: hyaluronic acid, tissue inhibitor of metalloproteinase 1 , and aminoterminal peptide of procollagen III. It has 3 cutoff values: (1) value 7.7 for exclusion of fibrosis, (2) value 9.8 for identification of fibrosis with sensitivity of $69 \%$ and specificity of $98 \%$ for moderate fibrosis, and (3) value 11.3 to discriminate cirrhosis with $83 \%$ sensitivity and specificity of 97\% [77].

J. FibroTest: This is calculated by using five biomarkers: haptoglobin, $\alpha 2$-macroglobulin, apolipoprotein A1, total bilirubin, and GGT. Cutoff value of 0.30 has $90 \%$ negative predictive value for advanced fibrosis with sensitivity of $77 \%$, and a cutoff value of 0.70 has a $73 \%$ positive predictive value for advanced fibrosis with specificity of $98 \%$. False positive result is seen in Gilbert's syndrome, cholestasis, acute hemolysis, renal insufficiency, on medications that may cause unconjugated hyperbilirubinemia, and acute liver inflammation [78].

K. Fibroindex: This simple scoring system is measured by using the following three biochemical markers: AST, platelet count, and gamma globulin. It has good specificity for mild or significant fibrosis (94\% and $97 \%$ respectively) but has low sensitivity (40\% and 36\% respectively) [79]. Due to its low sensitivity, it is not an adequate tool to be used alone for detection of hepatic fibrosis.

L. HepaScore: Age, sex, total bilirubin, GGT, alpha-2macroglobulin, and hyaluronic acid levels are used to calculate HepaScore. Score $\leq 0.2$ has $98 \%$ negative predictive value to exclude fibrosis and $\geq 0.8$ has a positive predictive value of $62 \%$ to predict cirrhosis [80].

M. Forns index: It has the following components: age, gamma-glutamyltransferase (GGT), cholesterol, and platelet count. Score $<4.25$ has a negative predictive value of $96 \%$ to exclude significant fibrosis and value $>6.9$ has positive predictive value of $66 \%$ for diagnosis of significant fibrosis [81].

N. Fibrospect II: This test (including hyaluronic acid, tissue inhibitor of a metalloproteinase-1 (TIMP-1), and alpha-2-macroglobulin as variables) can be used to predict stages of hepatic fibrosis (F2 to F4). Score $>0.42$ indicates presence of stage F2 to F4 fibrosis with sensitivity of $80.6 \%$ and specificity of $71.4 \%$ [82].

\section{Imagings for diagnosis of hepatic fibrosis}

A. Transient elastography (Fibroscan): This is an easyto-perform, non-invasive, day care procedure which takes about 5 to $10 \mathrm{~min}$ and measures the velocity of $50 \mathrm{MHz}$ shear wave that is emitted by ultrasound transducer probe and transmitted through hepatic tissue. This velocity of share wave in the liver is positively related to liver stiffness, and value ranges from 1.5 to $75 \mathrm{kPa}$. Fibroscan examines a larger area of liver tissue $(1 \mathrm{~cm}$ diameter $\times 5 \mathrm{~cm}$ in length) than liver biopsy and provides a more representative assessment of the entire hepatic parenchyma. Two types of probe are available to measure hepatic stiffness: " $\mathrm{M}$ " probe is the most commonly used to measure shear wave velocity, and "XL" probe is usually used in obese people to reduce the failure rate. Cutoff value of $<8 \mathrm{kPa}$ has a $94-100 \%$ negative predictive value to exclude significant hepatic fibrosis [83], and cutoff values used to identify stages of hepatic fibrosis are as follow: $7.1 \mathrm{kPa}$ for $\mathrm{F} \geq 2$, 9.5 $\mathrm{kPa}$ for $\mathrm{F} \geq 3$, and $12.5 \mathrm{kPa}$ for F4 [84]. Conditions which increase liver stiffness without fibrosis are acute hepatitis, hepatic congestion (e.g., in heart failure), mass lesions within the liver, and cholestasis. Failure or unreliable to take readings are seen more frequently in the following patients: obesity (BMI $\left.>30-35 \mathrm{~kg} / \mathrm{m}^{2}\right)$, older age, and presence of ascites. There are no absolute contraindications for this test, however manufacturer also advises against the use of this device in pregnancy and in patients with a pacemaker and implantable defibrillators. Despite these limitations, Fibroscan is one of the more reliable non-invasive methods to estimate liver fibrosis and is recommended during the management of NAFLD in the current guidelines [5]. 
B. Acoustic radiation force impulse (ARFI) elastography: ARFI uses a conventional B-mode ultrasonography probe which produces an acoustic pulse. Hepatic stiffness is expressed as shear wave velocity in meter per second $(\mathrm{m} / \mathrm{s})$ after calculating the median for 10 successful measures. Using a predictive shear stiffness of $4.24 \mathrm{kPa}$, it distinguishes low (fibrosis stage 0-2) from high (fibrosis stage 34) fibrosis stages with a sensitivity of $90 \%$ and a specificity of 90\% [85]. The advantages of ARFI are as follows: (1) the acoustic energy pulse is not affected by obesity or ascitic fluid, (2) specific regions of interest can be focused during procedure to measure varying depths in specific areas of the liver, (3) at the same time whole liver can be evaluated by ultrasonography which is not possible with Fbroscan. However, the presence of severe steatosis can affect accuracy of ARFI [86].

C. Shear wave elastography (SWE): By using conventional ultrasonography machine, SWE estimates liver stiffness in the right lobe and positively correlated with liver fibrosis severity and can potentially differentiate intermediate degrees of liver fibrosis in patients with NAFLD. Shear waves produced by a conventional ultrasound beam are directly related to the hepatic stiffness and are reported to be more accurate than transient elastography in assessing significant fibrosis of the liver (LS) ( $\geq$ F2) [87]. Hepatic stiffness is measured in the right lobe of the liver, and measurement of LS in the left lobe is inappropriate because it is affected by cardiac pulsation. In healthy population, liver stiffness value ranges in between 4.5 and 5.5 $\mathrm{kPa}$ [88]. Food intake increases LS value and results in falsely high fibrosis stages, and usually $180 \mathrm{~min}$ after food intake, value comes to the normal range; therefore, it is recommended to measure hepatic stiffness at least $4 \mathrm{~h}$ after food intake [89]. By using cut-off values of $7.10 \mathrm{kPa}$ and $9.1 \mathrm{kPa}$ to detect, $\mathrm{F} \geq$ 2 and $\mathrm{F} \geq 3$ have sensitivity and specificity of $93.8 \%$ and $52 \%$, and $93.1 \%$ and $80.8 \%$ respectively[85]. When $13 \mathrm{kPa}$ and $15.73 \mathrm{kPa}$ are used to detect F4 fibrosis, the sensitivity and specificity are 75.3 and 87.8 , and $100 \%$ and $82 \%$ respectively [90, 91].

D. Magnetic resonance elastography (MRE): It can assess a larger surface area of the liver or the entire liver than US-based modalities and is not limited by ascites and obesity. MRE has a sensitivity of $94 \%$ and specificity of $95 \%$ to differentiate F0 to F1 from F2 to F4, and $98 \%$ sensitivity and $94 \%$ specificity in differentiating F0 to F3 from F4 [92]. A cutoff value of $>3.63 \mathrm{kPa}$ has a sensitivity of $86 \%$, specificity of $91 \%$, NPV of $97 \%$, and PPV of $68 \%$ to discriminate advanced fibrosis (F3-F4) from stage F0 to F2 fibrosis [93]. Limitations of MRE are as follows: (1) it cannot be applied to individuals with hepatic iron overload due to the interfering signal intensity, (2) high cost of MRE, (3) needs further validations.

\section{Emerging genetic biomarkers for diagnosis of different stages of NAFLD}

Several genetic biomarkers were studied to diagnose or identify different stages of NAFLD. However, it needs further research before recommendations on emerging genetic biomarkers.

A. Lipidomic serum tests: These tests distinguish NAFLD from normal liver (NL) and NASH from non-alcoholic fatty liver (NAFL) with high accuracy. The diagnostic performances of the validated tests for discrimination between NAFLD and NL show sensitivity and specificity of 0.94 and 0.57 , respectively and sensitivity of 0.70 and specificity of 0.81 , respectively for the discrimination between NASH and NAFL [94]

B. Proteomic analysis: This analysis can be used to differentiate simple steatosis from NASH with significant fibrosis (F3/F4 group), and the NASH with significant fibrosis (F3/F4 group) and without significant fibrosis [95]. Complement component C7 was three-fold higher in the NASH group with significant/advanced fibrosis (F2-F4) compared with the early NASH (F0-F1). Complement component $\mathrm{C} 7$ and Fibulin-1 are positively correlated with liver stiffness, whereas complement component C8 $\gamma$ chain is negatively correlated. High levels of complement C7 are associated with NASH with significant/advanced fibrosis [96].

C. Gut microbiome-based metagenomic signature: Gut microbiome compositions using whole-genome shotgun sequencing of DNA extracted from stool can be used to identify advanced hepatic fibrosis in NAFLD patients. The gut microbiomes in NAFLD are dominated by members of Bacteroidetes and Firmicutes followed by Actinobacteria and Proteobacteria in much lower amount. Proteobacteria phylum has a statistically significant increase in amount (while the Firmicutes phylum decrease) as the disease progresses from mild/moderate NAFLD to advanced fibrosis [97].

\section{Management of NAFLD (Fig. 4)}

NALFD patients without NASH and hepatic fibrosis are treated by lifestyle changes which include diet modification and moderate physical exercise along with treatment of underlying causes. Pharmacotherapy is available in presence of NASH and fibrosis $(\geq 2)$. NAFLD patients with an advanced liver fibrosis (ELF 


\section{Non alcoholic fatty liver disease (NAFLD)}

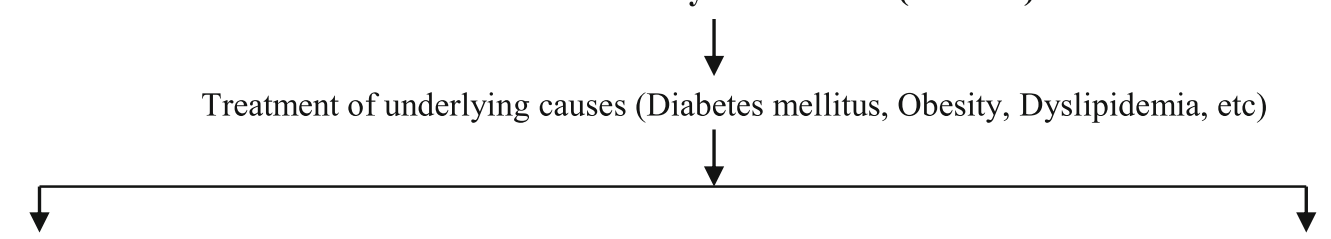

NAFLD without non alcoholic steatohepatitis (NASH) and significant fibrosis

Lifestyle modification:

A] Diet modification-

1. Energy restriction

2. Low calorie, low fat, and low carbohydrate diet

3. 500-1000 kcal deficit diet to induce a weight loss of 500-1000 gram/week

4. Coffee intake $\geq 2$ cups/day improves NAFLD by inhibiting proliferation of hepatic stellate cell

5. Fructose-containing beverages and foods should be avoided

6. Avoid alcohol consumption

7. Omega-3 fatty acid supplementation may be a new treatment option for NAFLD but Omega-3 fatty acid should not be used as a specific treatment of NAFLD or NASH, but it can be used to treat hypertriglyceridemia in NAFLD patients

\section{Plus}

B] Physical exercise-

1. Both moderate- vigorous aerobic exercise

At least $3 \%-5 \%$ of body weight loss is necessary to improve hepatic steatosis, but $>7 \%$ weight loss is required for histological improvement in NASH and fibrosis
NASH with significant fibrosis (fibrosis stage $\geq 2$ or fibroscan value $>10.51$ )

Lifestyle modifications

Plus

Physical exercise

Plus

One or more of the following medications:

1. Pioglitazone:

- Indicated in biopsy-proven NASH patients with and without type 2 diabetes mellitus

- $\quad 15-30 \mathrm{mg}$ daily dose of Pioglitazone is recommended

- Treatment should be stopped if there is no reduction in aminotransferases after 6 months of therapy and in patients with normal ALT at baseline, no recommendations can be made

2. Vitamin E:

- Vitamin E may be considered at a daily dose of $800 \mathrm{IU} /$ day in nondiabetic adults with biopsy-proven NASH

3. Ursodeoxycholic acid (UDCA):

- According to NICE, EASL, Asia-pacific and AASLD guidelines, UDCA is not recommended for treatment of NAFLD, NASH or hepatic fibrosis

- $\quad$ But few recent studies showed

(1) (Parikh P et al (2016) UDCA is an effective and safe alternative to Vitamin $\mathrm{E}$ in nondiabetic-non-cirrhotic Indian NAFLD patients

(2) (Mappala H, 2019) UDCA is a frontline therapeutic option for NASH and thereby preventing its progression to cirrhosis and liver cancer

Fig. 4 Medical management of non-alcoholic fatty liver disease

test > 10.51) a indication for pharmacotherapy in the NICE guideline [98]. Patients with NASH should be the main target of treatment due to higher risk of mortality related to the disease. A weight loss of at least $7 \%$ is required for histological improvement in obese NASH patients.
A. Lifestyle modification: It is an effective therapy to downgrade hepatic injury in NAFLD patients [99].

Diet modification: Energy restriction with a low calorie, low fat, and low carbohydrate or high-protein 
Mediterranean diet is advised in NAFLD patients. 500$1000 \mathrm{kcal}$ deficit diet per day to induce a weight loss of $500-1000 \mathrm{~g} /$ week is usually recommended (according to EASL, Asia-Pacific and AASLD guidelines). According to the Italian Association for the Study of the Liver (IASL), amount of fat and carbohydrate should be < $30 \%$ and $<50 \%$ of total calories respectively.

Coffee drinking is protective in NAFLD by reducing histological severity and liver-related outcomes and inversely related to the steatohepatitis severity [100]. Therefore daily coffee consumption should be encouraged in NAFLD patients. Coffee intake $\geq 2$ cups/day improves NAFLD and reduces liver-related morbidities [101]. Caffeine inhibits proliferation of hepatic stellate cell, thus exerting an anti-fibrogenic effect via adenosine receptor blockade [102].

Fructose-containing beverages and foods should be avoided because it appears as one major factor for initiation of hepatic steatosis and also its progression to NASH and more severe stages of the liver fibrosis [103, 104].

Alcohol intake should be $<30 \mathrm{~g} /$ day for men and $<20 \mathrm{~g} /$ day for women but better to avoid alcohol consumption of any type or amount in individuals with NAFLD [105].

Omega-3 fatty acid supplementation reduces hepatic steatosis and improves serum gamma-glutamyltransferase, triglyceride, and high-density lipoprotein in patients with NAFLD; therefore, omega-3 fatty acid supplementation may be a new treatment option for NAFLD [106, 107]. But according to AASLD guideline (2018), omega-3 fatty acid should not be used as a specific treatment of NAFLD or NASH, but it can be used to treat hypertriglyceridemia in NAFLD patients [5].

Physical exercise: Both moderate and vigorous aerobic exercise (e.g., brisk walking, stationery cycling) and resistance training (150-200 $\mathrm{min} /$ week in 3-5 sessions) is effective to reduce hepatic steatosis by reducing weight, and choice of exercise should be based on patients' preference [108]. In general, 5 to $10 \%$ reduction in body weight in obese or overweight people over 6 to 12 months has been advocated through diet modification and physical exercise.

At least $3-5 \%$ of body weight loss is necessary to improve hepatic steatosis, but $>7 \%$ weight loss is required for histological improvement in NASH and fibrosis [5].

Therefore, the first line intervention in the management of NAFLD is lifestyle modification which includes (1) at least $7-10 \%$ weight loss by a combination of lowcalorie diet with discourage of high fructose and saturated fat in foods. Diet with omega-3 fatty acid supplement may be advised, and (2) moderate to vigorous physical activity.

B. Pharmacotherapy: Only few drugs are recommended in the treatment of biopsy-proven
NASH and fibrosis stage $\geq 2$ or Fibroscan value > 10.51 .

Pioglitazone: It is a peroxisome proliferator-activated receptor (PPAR) gamma agonist which improves histological features in biopsy-proven NASH patients with and without type 2 diabetes mellitus. Fifteen to thirty milligrams daily dose of Pioglitazone is recommended in the above indication. The optimal duration of therapy is unknown, but according to EASL guideline [107], treatment should be stopped if there is no reduction in aminotransferases after 6 months of therapy, and in patients with normal ALT at baseline, no recommendations can be made. Bone loss in women and weight gain are common side effect associated with use of Pioglitazone. Bladder cancer has been a concern during use of Pioglitazone, but another study found that there is no statistically significant association between use of Pioglitazone and risk of bladder cancer [109]. Vitamin E: It is superior to placebo for the treatment of $\mathrm{NASH}$ in adults without diabetes, and compared with placebo, vitamin $\mathrm{E}$ use is associated with significantly higher rate of improvement in non-alcoholic steatohepatitis (43\% vs. $19 \%)$. It reduces hepatic steatosis and lobular inflammation, but no improvement in hepatic fibrosis scores [110]. According to AASLD and NICE guidelines, vitamin $\mathrm{E}$ may be considered at a dose of $800 \mathrm{IU} /$ day in nondiabetic adults with biopsy-proven NASH [5]. But according to Asia-Pacific guideline, vitamin E therapy is not beneficial for NASH management [111].

Saroglitazar: Saroglitazar (dual PPAR $\alpha / \gamma$ agonist) at a dose of $4 \mathrm{mg}$ improves ALT value and fatty liver (evaluated by transient elastography) in patients with NALFD and diabetic dyslipidemia [112]. Saroglitazar can be a potential therapeutic option for the management of metabolic syndrome associated NAFLD and NASH [113]. Another study from India with 12 months follow-up showed that Saroglitazar is safe and effective in management of NAFLD patients and is a potential option in the future [114]. But it needs further exploration before recommendation.

Liraglutide: It is a glucagon-like peptide-1 (GLP-1) ana$\log$ which is safe, well tolerated, and associated with histological improvement of non-alcoholic steatohepatitis with $1.8 \mathrm{mg}$ subcutaneous injections daily [115]. Most common side effects are diarrhea, constipation, and loss of appetite. However, it needs large studies for further evaluation for recommendation for the treatment of NAFLD.

Ursodeoxycholic acid (UDCA): Histological activities of NASH are not improved by using UDCA (13-15 mg/ $\mathrm{kg} /$ day) alone, but improvements are seen when 
combination of vitamin E and UDCA is given [116]. High-dose UDCA (23-28 mg/kg/day) also fails to improve the overall histology in patients with NASH [117]. According to NICE, EASL, Asia-pacific, and AASLD guidelines, UDCA is not recommended for treatment of NAFLD, NASH, or hepatic fibrosis however few recent articles showed positive results [118, 119]. Parikh et al. in their study indicated that UDCA is an effective and safe alternative to vitamin $E$ in nondiabetic-non-cirrhotic Indian NAFLD patients [118]. Another systemic review recommended UDCA as a frontline therapeutic option for NASH, thereby preventing its progression to cirrhosis and liver cancer [119].

Obeticholic acid: This synthetic farnesoid X receptor agonist at a dose of $25 \mathrm{mg}$ daily is associated with histological improvement of NASH [120, 121]. Obeticholic acid might become the first approved pharmacotherapy for NASH fibrosis after result of recent multicentre, randomized, placebo-controlled phase 3 trial done by Younossi et al. [122]. For longterm safety and tolerability, it requires further studies, as obeticholic acid can increase low density lipoprotein level and pruritus is also extremely common with high dose of obeticholic acid.

Statin and n-3 polyunsaturated fatty acids: There are no data to support their use specifically for NASH. SGLT-2 inhibitors: These drugs improve the serum liver enzymes value and reduce hepatic steatosis and fibrosis in type 2 diabetes patients with NAFLD [123]. Therefore use of SGLT2-inhibitors in type 2 diabetes patients with NAFLD is promising. Further researches are required to progress in this evolving field.

\section{Others emerging drugs for management of NAFLD:}

Elafibranor: It is a peroxisome proliferator-activated receptor- $\alpha$ and peroxisome proliferator-activated receptor- $\delta$ agonist and improves insulin sensitivity, glucose homeostasis, and lipid metabolism, and reduces inflammation. Ratziu et al. in their study showed that elafibranor $(120 \mathrm{mg} /$ day for 1 year) resolved NASH without fibrosis worsening [124]. It has an effect on the resolution on NASH and improvises two key drivers of NASH progression-insulin resistance and serum lipid normalization [125]. It induces nuclear factor- $\kappa B$ results in inhibition of inflammatory genes and decreases the expression of acute-phase response genes [126]. It causes reversible elevation of serum creatinine level; therefore, its use is potentially limiting in patients with concurrent renal disease. Common side effects are congestive heart failure, peripheral edema, bone fractures, and weight gain.
Lanifibranor (IVA337): It is a pan-peroxisome proliferator-activated receptor (PPAR) agonist with moderate and well-balanced activity on the three PPAR isoforms $(\alpha, \gamma, \delta)$. It inhibits proliferation and activation of hepatic stellate cells which are the key cells driving liver fibrogenesis in NASH. It improves liver histology by decreasing liver steatosis, inflammation, and ballooning. Wettstein et al. in their study indicated that lanifibranor has therapeutic potential in the treatment of NASH [127].

Solithromycin: Solithromycin is a highly potent macrolide antibiotic. A clinical trial is going on (NCT02510599) which showed that there is reduction of NAFLD activity score and ALT level after 90 days treatment with Solithromycin in patients with NASH by targeting intestinal microbiomes and metabolic endotoxemia.

Cenicrivoric: Cenicriviroc is a $\mathrm{CCR}(\mathrm{C}-\mathrm{C}$ chemokine receptor) 2 and CCR5 dual antagonist which is playing an important role in macrophage recruitment and polarization in NASH pathogenesis. One phase 2 trial (2018) showed that there was improvement in fibrosis and no worsening of steatohepatitis compared with placebo [128]. Therefore, the drug is now in phase 3. Selonsertib: It is an apoptosis signal-regulating kinase 1 (ASK1, involved in response to various stresses) inhibitor. Loomba et al. in their phase 2 trial described that selonsertib may reduce liver fibrosis in patients with non-alcoholic steatohepatitis and stage 2-3 fibrosis [129]. Now this drug is in phase 3 trial.

Emricasan: It is an oral pan-caspase inhibitor. Lipotoxicity leading to excessive caspase-mediated apoptosis and inflammation is responsible of liver damage in NAFLD. Shiffman et al. in their study showed that emricasan (25 mg twice daily) decreases ALT and biomarkers in NAFLD patients after 28 days of treatment [130].

C. Management of underlying diseases: Along with above treatment, underlying causes of NAFLD should be treated adequately like management of each component of metabolic syndrome if present.

\section{Conclusion}

Though liver biopsy is the gold standard test to detect NAFLD and to identify different stages of hepatic steatosis and fibrosis, multiple non-invasive tests are also available nowadays. Few of them are FDA approved and others' diagnostic tests need further evaluation before recommendation in clinical practice. The NAFLD fibrosis score, transient elastography are recommended to assess hepatic fibrosis and disease activity [5] however for diagnosis of NASH, liver biopsy is required due to lack of 
availability of serum cytokeratine 19 fragments test in clinical practice. Further studies are required to find out cutoff values and role of non-invasive markers and tests for NAFLD before giving approval. Liver biopsy should be considered in the following conditions: (1) when a competing etiology of chronic liver disease cannot be excluded just by non-invasive methods, (2) suspect of NAFLD-related advanced liver disease. Treatment of NAFLD can be divided into lifestyle modification (including diet restriction, low calorie diet intake, physical exercise leading to weight loss), pharmacotherapy (restricted to NAFLD patients with NASH and fibrosis), and management of underlying causes of NAFLD. Early diagnosis and proper management are required to avoid longterm complications of NAFLD.

\section{Abbreviations}

NAFLD: Non-alcoholic fatty liver disease; LFT: Liver function test; USG: Ultrasonography; CAP: Controlled attenuation parameter; BMI: Body mass index; CT scan: Computed tomography; MRI: Magnetic resonance imaging; 1H-MRS: Hydrogen-1 MR spectroscopy; PDFF: Proton density fat fraction; 31P- MRS: Hepatic phosphorus-31 MRS; GGT: Gammaglutamyltransferase; ALT: Alanine aminotransferase; AST: Aspartate aminotransferase; NLFS: NAFLD liver fat score; FLI: Fatty liver index; HSI: Hepatic steatosis index; T2DM: Type 2 diabetes mellitus; LAP: Lipid accumulation product; NAFL: Non-alcoholic fatty liver; NASH: Non-alcoholic steatohepatitis; CK: Serum cytokeratin; FGF21: Fibroblast growth factor 21; PPV: Positive predictive value; NPV: Negative predictive value; NDI: NASH diagnostic index; MS: Metabolic syndrome; NPI: NASH predictive index; HOMA: Homeostatic model assessment; 1H-MRS: Proton magnetic resonance; MRE: Magnetic resonance elastography; APRI: Aspartate aminotransferase/platelet ratio index; NFS: NAFLD fibrosis score; Fl: Fibrosis index score; ELF: Enhanced liver fibrosis; ARFI: Acoustic radiation force impulse; SWE: Shear wave elastography; LS: Liver stiffness; MRE: Magnetic resonance elastography; UDCA: Ursodeoxycholic acid; SGLT-2 inhibitor: Sodium-glucose cotransporter-2 inhibitor; FDA: Food and Drug Administration

\section{Acknowledgements}

Not applicable.

\section{Author's contributions}

The author contributed in the interpretation of the study data, manuscript writing, and revising. The author read and approved the final manuscript.

\section{Funding}

Nil

Availability of data and materials

Data materials are available under reasonable request.

\section{Ethics approval and consent to participate}

Not applicable.

\section{Consent for publication}

Not applicable.

\section{Competing interests}

The author declares that he has no competing interests.

Received: 16 March 2020 Accepted: 1 July 2020

Published online: 28 July 2020

\section{References}

1. Armstrong MJ, Houlihan DD, Bentham L et al (2012) Presence and severity of non-alcoholic fatty liver disease in a large prospective primary care cohort. J Hepatol 56:234-240
2. Farrell GC, Wong WW, Chitturi S (2013) NAFLD in Asia--as common and important as in the West. Nat Rev Gastroenterol Hepatol 10:307-318

3. Younossi ZM, Koenig AB, Abdelatif D et al (2016) Global epidemiology of nonalcoholic fatty liver disease-meta analytic assessment of prevalence, incidence, and outcomes. Hepatology 64:73-84

4. Singh SP, Nayak S, Swain M et al (2004) Prevalence of nonalcoholic fatty liver disease in coastal eastern India: a preliminary ultrasonographic survey. Indian J Gastroenterol. 25:76-79

5. Chalasani N, Younossi Z, Lavine JE et al (2018 Jan) The diagnosis and management of nonalcoholic fatty liver disease: practice guidance from the American Association for the Study of Liver Diseases. Hepatology. 67:328357

6. Matteoni CA, Younossi ZM, Gramlich T et al (1999) Nonalcoholic fatty liver disease: a spectrum of clinical and pathological severity. Gastroenterology. 116:1413-1419

7. Brunt EM (2001) Nonalcoholic steatohepatitis: definition and pathology. Semin Liver Dis 21:3-16

8. Van Werven JR, Marsman HA, Nederveen AJ et al (2010) Assessment of hepatic steatosis in patients undergoing liver resection: comparison of US, CT, T1-weighted dual-echo MR imaging, and point-resolved 1H MR spectroscopy. Radiology 256:159-168

9. Joseph AE, Saverymuttu SH, al-Sam S, et al. Comparison of liver histology with ultrasonography in assessing diffuse parenchymal liver disease. Clin Radiol 1991; 43:26-31.

10. Dasarathy S, Dasarathy J, Khiyami A et al (2009) Validity of real time ultrasound in the diagnosis of hepatic steatosis: a prospective study. J Hepatol 51:1061-1067

11. Shiralkar K, Johnson S, Bluth El, Marshall RH, Dornelles A, Gulotta PM (2015) Improved method for calculating hepatic steatosis using the hepatorenal index. J Ultrasound Med. 34:1051-1059

12. Ballestri S, Lonardo A, Romagnoli D et al (2012) Ultrasonographic fatty liver indicator, a novel score which rules out NASH and is correlated with metabolic parameters in NAFLD. Liver Int 32:1242-1252

13. Chan WK, Nik Mustapha NR, Mahadeva S (2014) Controlled attenuation parameter for the detection and quantification of hepatic steatosis in nonalcoholic fatty liver disease. J Gastroenterol Hepatol 29:1470-1476

14. Ahn JM, Paik YH, Min SY et al (2016) Relationship between controlled attenuation parameter and hepatic steatosis as assessed by ultrasound in alcoholic or nonalcoholic fatty liver disease. Gut Liver 10:295-302

15. Yen YH, Chen JF, Wu CK et al (2017) The correlation of controlled attenuation parameter results with ultrasound-identified steatosis in realworld clinical practice. J Formos Med Assoc. 116:852-861

16. Machado MV (2017) Controlled attenuation parameter as a noninvasive method to detect and quantify hepatic steatosis in chronic liver disease: what is the clinical relevance? GE Port J Gastroenterol. 24:157-160

17. Sasso M, Beaugrand M, Ledinghen $V$ et al (2010) Controlled attenuation parameter (CAP): a novel VCTE (TM) guided ultrasonic attenuation measurement for the evaluation of hepatic steatosis: preliminary study and validation in a cohort of patients with chronic liver disease from various causes. Ultrasound Med Biol. 36:1825-1835

18. Liu K, Wong W, Lau K et al (2017) Prognostic value of controlled attenuation parameter by transient elastography. Am J Gastroenterol 112: 1812-1823

19. Shin J, Kim MJ, Shin HJ et al (2019) Quick assessment with controlled attenuation parameter for hepatic steatosis in children based on MRI-PDFF as the gold standard. BMC Pediatr 19:112

20. Valls C, lannacconne R, Alba E et al (2006) Fat in the liver: diagnosis and characterization. Eur Radiol. 16(10):2292e308

21. Kani KK, Moshiri M, Cuevas C et al (2012) Imaging patterns of hepatic steatosis on multidetector CT: pearls and pitfalls. Clin Radiol. 67(4):366-371

22. Lee SW, Park SH, Kim KW et al (2007) Unenhanced CT for assessment of macrovesicular hepatic steatosis in living liver donors: comparison of visual grading with liver attenuation index. Radiology 244:479-485

23. Lee SS, Park SH, Kim HJ et al (2010) Non-invasive assessment of hepatic steatosis: prospective comparison of the accuracy of imaging examinations. Jepatol 52:579-585

24. Bley TA, Wieben O, François CJ et al (2010) Fat and water magnetic resonance imaging. J Magn Reson Imaging 31:4-18

25. Georgoff P, Thomasson D, Louie A et al (2012) Hydrogen-1 MR spectroscopy for measurement and diagnosis of hepatic steatosis. AJR Am J Roentgenol. 199:2-7 
26. Paparo F, Cenderello G, Revelli M et al (2015) Diagnostic value of MRI proton density fat fraction for assessing liver steatosis in chronic viral $\mathrm{C}$ hepatitis. Biomed Res Int. 2015:758164

27. Sevastianova K, Hakkarainen A, Kotronen A et al (2010) Nonalcoholic fatty liver disease: detection of elevated nicotinamide adenine dinucleotide phosphate with in vivo 3.0-T 31P MR spectroscopy with proton decoupling. Radiology. 256(2):466-473

28. Al-Busafi SA, Ghali P, Wong P et al (2012) The utility of Xenon-133 liver scan in the diagnosis and management of nonalcoholic fatty liver disease. Can J Gastroenterol 26:155-159

29. Ruhl CE, Everhart JE (2009) Elevated serum alanine aminotransferase and gamma-glutamyltransferase and mortality in the United States population. Gastroenterology 136:477-485

30. Kotronen A, Peltonen M, Hakkarainen A et al (2009) Prediction of nonalcoholic fatty liver disease and liver fat using metabolic and genetic factors. Gastroenterology 137:865-872

31. Unalp-Arida A, Ruhl CE (2018) Liver fat scores predict liver disease mortality in the United States population. Aliment Pharmacol Ther. 48(9):1003-1016

32. Bedogni $G$, Bellentani $S$, Miglioli $L$ et al (2006) The fatty liver index: a simple and accurate predictor of hepatic steatosis in the general population. BMC Gastroenterol. 6:33

33. Sviklāne L, Olmane E, Dzērve $Z$ et al (2018) Fatty liver index and hepatic steatosis index for prediction of non-alcoholic fatty liver disease in type 1 diabetes. J Gastroenterol Hepatol 33:270-276

34. Bedogni G, Kahn HS, Bellentani S et al (2010) A simple index of lipid over accumulation is a good marker of liver steatosis. BMC Gastroenterol 10:98

35. Dai H, Wang W, Chen R et al (2017) Lipid accumulation product is a powerful tool to predict non-alcoholic fatty liver disease in Chinese adults. Nutr Metab (Lond) 14:49

36. Cheng YL, Wang YJ, Lan KH et al (2017) Fatty liver index and lipid accumulation product can predict metabolic syndrome in subjects without fatty liver disease. Gastroenterol Res Pract. 2017:9279836

37. Poynard T, Ratziu V, Naveau S et al (2005) The diagnostic value of biomarkers (SteatoTest) for the prediction of liver steatosis. Comp Hepatol. 4:10

38. Zhou YJ, Zhou YF, Zheng JN et al (2017) NAFL screening score: a basic score identifying ultrasound-diagnosed non-alcoholic fatty liver. Clin Chim Acta 475:44-50

39. Machado MV, Cortez-Pinto H (2013) Non-invasive diagnosis of non-alcoholic fatty liver disease. A critical appraisal. J Hepatol. 58:1007-1019

40. Maher MM, Ibrahim WA, Saleh SA et al (2014) Cytokeratin 18 as a non invasive marker in diagnosis of NASH and its usefulness in correlation with disease severity in Egyptian patients. Egypt j med hum Genet 16:41-46

41. Aida Y, Abe H, Tomita Y et al (2014) Serum cytokeratin 18 fragment level as a noninvasive biomarker for non-alcoholic fatty liver disease. Int J Clin Exp Med 7:4191-4198

42. Verma S, Jensen D, Hart J et al (2013) Predictive value of ALT levels for nonalcoholic steatohepatitis (NASH) and advanced fibrosis in nonalcoholic fatty liver disease (NAFLD). Liver Int 33:1398-1405

43. Mofrad P, Contos MJ, Haque M et al (2003) Clinical and histologic spectrum of nonalcoholic fatty liver disease associated with normal ALT values. Hepatology. 37:1286-1292

44. Bechmann LP, Kocabayoglu P, Sowa JP et al (2013) Free fatty acids repress small heterodimer partner (SHP) activation and adiponectin counteracts bile acid-induced liver injury in superobese patients with nonalcoholic steatohepatitis. Hepatology. 57:1394-1406

45. Barb D, Bril F, Kalavalapalli S et al (2019) Plasma fibroblast growth factor 21 is associated with severity of nonalcoholic steatohepatitis in patients with obesity and type 2 diabetes. J Clin Endocrinol Metab. 104:3327-3336

46. Shen J, Chan HL, Wong GL et al (2012) Non-invasive diagnosis of non-alcoholic steatohepatitis by combined serum biomarkers. J Hepatol 56:1363-1370

47. Paquette M, Gauthier D, Chamberland A et al (2020) Circulating PCSK9 is associated with liver biomarkers and hepatic steatosis. Clin Biochem. 77:20-25

48. Ruscica M, Ferri N, Macchi C et al (2016) Liver fat accumulation is associated with circulating PCSK9. Ann Med. 48(5):384-391

49. Yoneda M, Uchiyama T, Kato $S$ et al (2008) Plasma pentraxin3 is a novel marker for nonalcoholic steatohepatitis (NASH). BMC Gastroenterol. 8:53

50. Casoinic F, Sampelean D, Buzoianu AD et al (2016) Serum levels of oxidative stress markers in patients with type 2 diabetes mellitus and non-alcoholic steatohepatitis. Rom J Intern Med. 54(4):228-236

51. Tilg H, Moschen AR, Roden M (2017) NAFLD and diabetes mellitus. Nat Rev Gastroenterol Hepatol. 14(1):32-42
52. Jamali R, Arj A, Razavizade M, Aarabi MH (2016) Prediction of nonalcoholic fatty liver disease via a novel panel of serum adipokines. Medicine (Baltimore). 95(5):e2630

53. Yoneda M, Mawatari H, Fujita K et al (2007) High-sensitivity C-reactive protein is an independent clinical feature of nonalcoholic steatohepatitis (NASH) and also of the severity of fibrosis in NASH. J Gastroenterol. 42(7):573-582

54. Poynard T, Ratziu V, Charlotte F et al (2006) Diagnostic value of biochemical markers (NashTest) for the prediction of non alcoholo steato hepatitis in patients with non-alcoholic fatty liver disease. BMC Gastroenterol 6:34

55. Zhou $Y$, Orešič $M$, Leivonen $M$ et al (2016) Noninvasive detection of nonalcoholic steatohepatitis using clinical markers and circulating levels of lipids and metabolites. Clin Gastroenterol Hepatol 14:1463-1472

56. Mauss S, Berg T, Rockstroh J et al (2018) Hepatology - a clinical textbook, 3rd edn, Germany

57. Younossi ZM, Otgonsuren M, Hunt S et al (2013) Development and validation of Nash diagnostic index as a non-invasive model for diagnosing non-alcoholic steatohepatitis (Nash). J Hepatol 58:S409-\$566

58. Anty R, lannelli A, Patouraux S et al (2010) A new composite model including metabolic syndrome, alanine aminotransferase and cytokeratin-18 for the diagnosis of non-alcoholic steatohepatitis in morbidly obese patients. Aliment Pharmacol Ther. 32:1315-1322

59. Palekar NA, Naus R, Larson SP et al (2006) Clinical model for distinguishing non-alcoholic steatohepatitis from simple steatosis in patients with nonalcoholic fatty liver disease. Liver Int. 26:151-156

60. Sumida $Y$, Yoneda M, Hyogo $\mathrm{H}$ et al (2011) A simple clinical scoring system using ferritin, fasting insulin, and type IV collagen 75 for predicting steatohepatitis in nonalcoholic fatty liver disease. J Gastroenterol 46:257-268

61. Zein CO, Edmison JM, Schluchter M, et al. A NASH predictive index (NPI) for use in patients with nonalcoholic fatty liver disease [abstract] Hepatology. 2007; 46:747A

62. Gholam PM, Flancbaum L, Machan JT et al (2007) Nonalcoholic fatty liver disease in severely obese subjects. Am J Gastroenterol 102:399-408

63. Alkhouri N, Berk M, Yerian L et al (2014) OxNASH score correlates with histologic features and severity of nonalcoholic fatty liver disease. Digestive diseases and sciences. 59:1617-1624

64. Chunming L, Jianhui S, Hongguang $Z$ et al (2015) The development of a clinical score for the prediction of nonalcoholic steatohepatitis in patients with nonalcoholic fatty liver disease using routine parameters. Turk J Gastroenterol 26:408-416

65. Hyysalo J, Mannisto VT, Zhou Y et al (2014) A population based study on the prevalence of NASH using scores validated against liver histology. J Hepatol 60:839-846

66. Verdam FJ, Dallinga JW, Driessen A et al (2013) Nonalcoholic steatohepatitis: a non-invasive diagnosis by analysis of exhaled breath. Journal of hepatology. 58:543-548

67. Kim $\mathrm{TH}$, Jeong $\mathrm{CW}$, Jun $\mathrm{HY}$ et al (2019) Accuracy of proton magnetic resonance for diagnosing non-alcoholic steatohepatitis: a meta-analysis. Scientific Reports 9:15002

68. Chen J, Talwalkar JA, Yin M et al (2011) Early detection of non-alcoholic steatohepatitis in patients with non-alcoholic fatty liver disease by using MR elastography. Radiology. 259:749-756

69. Lin ZH, Xin YN, Dong QJ et al (2011) Performance of the aspartate aminotransferase-to-platelet ratio index for the staging of hepatitis C-related fibrosis: an updated meta-analysis. Hepatology. 53:726-736

70. Vallet-Pichard A, Mallet V, Nalpas B et al (2007) FIB-4: An inexpensive and accurate marker of fibrosis in HCV infection. Comparison with liver biopsy and fibrotest. Hepatology. 46:32-36

71. Harrison SA, Oliver D, Arnold HL et al (2008) Development and validation of a simple NAFLD clinical scoring system for identifying patients without advanced disease. Gut. 57:1441-1447

72. Angulo P, Hui JM, Marchesini G et al (2007) The NAFLD fibrosis score: a noninvasive system that identifies liver fibrosis in patients with NAFLD. Hepatology. 45:846-854

73. Cross TJ, Rizzi P, Berry PA et al (2009) King's score: an accurate marker of cirrhosis in chronic hepatitis C. Eur J Gastroenterol Hepatol. 21:730-738

74. Ohta T, Sakaguchi K, Fujiwara A et al (2006) Simple surrogate index of the fibrosis stage in chronic hepatitis $C$ patients using platelet count and serum albumin level. Acta Med Okayama. 60:77-84

75. Cao W, Zhao C, Shen C et al (2013) Cytokeratin 18, alanine aminotransferase, platelets and triglycerides predict the presence of nonalcoholic steatohepatitis. PLoS One. 8:e82092 
76. Alboraie M, Khairy M, Elsharkawy A et al (2014) Egy-Score as a noninvasive score for the assessment of hepatic fibrosis in chronic hepatitis C: a preliminary approach. Saudi J Gastroenterol. 20:170-174

77. Lichtinghagen $\mathrm{R}$, Pietsch D, Bantel $\mathrm{H}$ et al (2013) The enhanced liver fibrosis (ELF) score: normal values, influence factors and proposed cut-off values. J Hepatol 59:236-242

78. Ratziu V, Massard J, Charlotte F et al (2006) Diagnostic value of biochemical markers (FibroTest-FibroSURE) for the prediction of liver fibrosis in patients with non-alcoholic fatty liver disease. BMC Gastroenterol. 6:6

79. Koda M, Matunaga Y, Kawakami M et al (2007) Fibrolndex, a practical index for predicting significant fibrosis in patients with chronic hepatitis $C$. Hepatology. 45:297-306

80. Becker L, Salameh W, Sferruzza A et al (2009) Validation of hepascore, compared with simple indices of fibrosis, in patients with chronic hepatitis C virus infection in United States. Clin Gastroenterol Hepatol. 7:696-701

81. Forns $X$, Ampurdanès S, Llovet JM et al (2002) Identification of chronic hepatitis $C$ patients without hepatic fibrosis by a simple predictive model. Hepatology. 36:986-992

82. Patel K, Gordon SC, Jacobson I et al (2004) Evaluation of a panel of noninvasive serum markers to differentiate mild from moderate-to-advanced liver fibrosis in chronic hepatitis C patients. J Hepatol. 41:935-942

83. Petta S, Wong WW, Camma C et al (2017) Serial combination of non-invasive tools improves the diagnostic accuracy of severe liver fibrosis in patients with NAFLD. Aliment Pharmacol Ther 46:617-627

84. Castera L, Vergniol J, Foucher J et al (2005) Prospective comparison of transient elastography, Fibrotest, APRI, and liver biopsy for the assessment of fibrosis in chronic hepatitis C. Gastroenterology. 128:343-350

85. Palmeri ML, Wang MH, Rouze NC et al (2011) Noninvasive evaluation of hepatic fibrosis using acoustic radiation force-based shear stiffness in patients with nonalcoholic fatty liver disease. J Hepatol. 55:666-672

86. Joo SK, Kim W, Kim D et al (2018) Steatosis severity affects the diagnostic performances of noninvasive fibrosis tests in nonalcoholic fatty liver disease. Liver Int 38:331-341

87. Frulio N, Trillaud H (2013) Ultrasound elastography in liver. Diagn Interv Imaging. 94:515-534

88. Lemoine M, Shimakawa Y, Njie R et al (2014) Food intake increases liver stiffness measurements and hampers reliable values in patients with chronic hepatitis B and healthy controls: the PROLIFICA experience in The Gambia. Aliment Pharmacol Ther. 39:188-196

89. Mederacke I, Wursthorn K, Kirschner J et al (2009) Food intake increases liver stiffness in patients with chronic or resolved hepatitis $C$ virus infection. Liver Int. 29:1500-1506

90. Herrmann $E$, de Lédinghen V, Cassinotto $C$ et al (2018) Assessment of biopsy-proven liver fibrosis by two-dimensional shear wave elastography: an individual patient data-based meta-analysis. Hepatology. 67:260-272

91. Takeuchi H, Sugimoto K, Oshiro H et al (2018) Liver fibrosis: noninvasive assessment using supersonic shear imaging and FIB4 index in patients with non-alcoholic fatty liver disease. J Med Ultrason 45:243-249

92. Wang QB, Zhu H, Liu HL et al (2012) Performance of magnetic resonance elastography and diffusion-weighted imaging for the staging of hepatic fibrosis: a meta-analysis. Hepatology. 56:239-247

93. Loomba R, Wolfson T, Ang B et al (2014) Magnetic resonance elastography predicts advanced fibrosis in patients with nonalcoholic fatty liver disease: a prospective study. Hepatology. 60:1920-1928

94. Mayo R, Crespo J, Martínez-Arranz I et al (2018) Metabolomic-based noninvasive serum test to diagnose nonalcoholic steatohepatitis: results from discovery and validation cohorts. Hepatol Commun. 2(7):807-820

95. Bell LN, Theodorakis JL, Vuppalanchi R et al (2010) Serum proteomics and biomarker discovery across the spectrum of nonalcoholic fatty liver disease. Hepatology. 51(1):111-120

96. Hou W, Janech MG, Sobolesky PM,et al. Proteomic screening of plasma identifies potential noninvasive biomarkers associated with significant/ advanced fibrosis in patients with nonalcoholic fatty liver disease. Biosci Rep. 2020; 40 (1): BSR20190395

97. Loomba R, Seguritan V, Li W, et al. Gut microbiome-based metagenomic signature for non-invasive detection of advanced fibrosis in human nonalcoholic fatty liver disease. Cell Metab. 2017; 25(5):1054-1062.e5.

98. National Institute for Health and Care Excellence (UK). Non alcoholic fatty liver disease: assessment and management. Available from: URL: http// www.niceorg.uklguidancelng49
99. Paul J, Venugopal RV, Peter L et al (2018) Effects of lifestyle modification on liver enzyme and Fibroscan in Indian patients with non-alcoholic fatty liver disease. Gastroenterol Rep (Oxf). 6:49-53

100. Saab S, Mallam D (2014) Cox 2nd GA, et al. Impact of coffee on liver diseases: a systematic review. Liver Int 34:495-504

101. Setiawan WW, Porcel J, Wei P et al (2017) Coffee drinking and alcoholic and nonalcoholic fatty liver diseases and viral hepatitis in the multiethnic cohort. Clin Gastroenterol Hepatol. 15(8):1305-1307

102. Salomone F, Galvano F, Li VG (2017) Molecular bases underlying the hepatoprotective effects of coffee. Nutrients. 9(1):85

103. Jegatheesan P, De Bandt JP (2017) Fructose and NAFLD: the multifaceted aspects of fructose metabolism. Nutrients. 9:230

104. Vos MB, Lavine JE (2013) Dietary fructose in nonalcoholic fatty liver disease. Hepatology 57:2525-2531

105. Liangpunsakul S, Chalasani N (2012) What should we recommend to our patients with NAFLD regarding alcohol use? Am J Gastroenterol 107:976-978

106. Wenxia Lu, Sainan Li, Jingjing Li, et al. Effects of omega-3 fatty acid in nonalcoholic fatty liver disease: a meta-analysis. Gastroenterol Res Pract 2016; 2016: 1459790.

107. Yan JH, Guan BJ, Gao HY et al (2018) Omega-3 polyunsaturated fatty acid supplementation and non-alcoholic fatty liver disease: a meta-analysis of randomized controlled trials. Medicine (Baltimore). 97(37):e12271

108. Marchesini G, Day CP, Dufour JF et al (2016) EASL-EASD-EASO clinical practice guidelines for the management of non-alcoholic fatty liver disease. J Hepatol. 64:1388-1402

109. Lewis JD, Habel LA, Quesenberry CP et al (2015) Pioglitazone use and risk of bladder cancer and other common cancers in persons with diabetes. JAMA 314:265-277

110. Sanyal AJ, Chalasani N, Kowdley KV et al (2010) Pioglitazone, vitamin E, or placebo for nonalcoholic steatohepatitis. N Engl J Med. 362:1675-1685

111. Chitturi S, Wong W, Chan WK et al (2018) The Asia-Pacific Working Party on Non-alcoholic Fatty Liver Disease guidelines 2017-part 2: management and special groups. J Gastroenterol Hepatol 33:86-98

112. Kaul U, Parmar D, Manjunath $\mathrm{K}$ et al (2019) New dual peroxisome proliferator activated receptor agonist-Saroglitazar in diabetic dyslipidemia and non-alcoholic fatty liver disease: integrated analysis of the real world evidence. Cardiovasc Diabetol 18:80. https://doi.org/10.1186/s12933-0190884-3

113. Joshi S, Ruby S, Saboo B, et al. Saroglitazar in non-alcoholic fatty liver disease. The American Association of Clinical Endocrinologists Annual Meeting Abstracts. Late breaking abstracts; 2016, p. 331.

114. Dadhich SK. Efficacy and safety of Saroglitazar in nonalcoholic fatty liver disease patients at 1 year: an investigator initiated study. American College of Gastroenterology Annual Scientific Meeting Abstracts; 2019, p. 1541.

115. Armstrong MJ, Gaunt P, Aithal GP et al (2016) Liraglutide safety and efficacy in patients with non-alcoholic steatohepatitis (LEAN): a multicentre, double blind, randomised, placebo-controlled phase 2 study. Lancet 387:679-690

116. Dufour JF, Oneta CM, Gonvers JJ et al (2006) Randomized placebocontrolled trial of ursodeoxycholic acid with vitamin $\mathrm{E}$ in nonalcoholic steatohepatitis. Clin Gastroenterol Hepatol 4:1537-1543

117. Leuschner UF, Lindenthal B, Herrmann G et al (2010) High-dose ursodeoxycholic acid therapy for nonalcoholic steatohepatitis: a doubleblind, randomized, placebo-controlled trial. Hepatology 52:472-479

118. Parikh $P$, Ingle M, Patel J et al (2016) An open-label randomized control study to compare the efficacy of vitamin e versus ursodeoxycholic acid in nondiabetic and noncirrhotic Indian NAFLD patients. Saudi J Gastroenterol 22(3):192-197

119. Mappala H (2019) IDDF2019-ABS-0251 The efficacy of ursodeoxycholic acid in the treatment of non-alcoholic steatohepatitis: a 15-year systematic review. Gut 68:A152

120. Neuschwander-Tetri BA, Loomba R, Sanyal AJ et al (2015) Farnesoid X nuclear receptor ligand obeticholic acid for non-cirrhotic, non-alcoholic steatohepatitis (FLINT): a multicentre, randomised, placebo-controlled trial. Lancet 385:956-965

121. Hindson J (2020) Obeticholic acid for the treatment of NASH. Nat Rev Gastroenterol Hepatol. 17(2):66

122. Younossi ZM, Ratziu V, Loomba R et al (2019) Obeticholic acid for the treatment of non-alcoholic steatohepatitis: interim analysis from a multicentre, randomised, placebo-controlled phase 3 trial. Lancet. 394(10215):2184-2196 
123. Raj H, Durgia H, Palui R et al (2019) SGLT-2 inhibitors in non-alcoholic fatty liver disease patients with type 2 diabetes mellitus: a systematic review. World J Diabetes 10:114-132

124. Ratziu V, Harrison SA, Francque $S$ et al (2016) Elafibranor, an agonist of the peroxisome proliferator-activated receptor-a and $-\delta$, induces resolution of nonalcoholic steatohepatitis without fibrosis worsening. Gastroenterology. 150(5):1147-1159

125. Westerouen Van Meeteren MJ, Drenth JPH, Tjwa ETTL (2020) Elafibranor: a potential drug for the treatment of nonalcoholic steatohepatitis (NASH). Expert Opin Investig Drugs. 29(2):117-123

126. Pawlak M, Lefebvre P, Staels B (2015) Molecular mechanism of PPARa action and its impact on lipid metabolism, inflammation and fibrosis in nonalcoholic fatty liver disease. J Hepatol. 62(3):720-733

127. Wettstein $G$, Luccarini JM, Poekes $L$ et al (2017) The new-generation panperoxisome proliferator-activated receptor agonist IVA337 protects the liver from metabolic disorders and fibrosis. Hepatol Commun. 1(6):524-537

128. Friedman SL, Ratziu V, Harrison SA et al (2018) A randomized, placebocontrolled trial of cenicriviroc for treatment of nonalcoholic steatohepatitis with fibrosis. Hepatology. 67(5):1754-1767

129. Loomba R, Lawitz E, Mantry PS et al (2018) The ASK1 inhibitor selonsertib in patients with nonalcoholic steatohepatitis: a randomized, phase 2 trial. Hepatology. 67(2):549-559

130. Shiffman M, Freilich B, Vuppalanchi R et al (2019) Randomised clinical trial: emricasan versus placebo significantly decreases ALT and caspase 3/7 activation in subjects with non-alcoholic fatty liver disease. Aliment Pharmacol Ther. 49(1):64-73

\section{Publisher's Note}

Springer Nature remains neutral with regard to jurisdictional claims in published maps and institutional affiliations.

\section{Submit your manuscript to a SpringerOpen ${ }^{\circ}$ journal and benefit from:}

- Convenient online submission

- Rigorous peer review

- Open access: articles freely available online

- High visibility within the field

- Retaining the copyright to your article

Submit your next manuscript at $\boldsymbol{\nabla}$ springeropen.com 